\title{
Influence of Postharvest Handling on the Concentration of Pesticide Residues in Peach Peel
}

\author{
Kathryn C. Taylor ${ }^{1}$ \\ Horticulture Department, University of Georgia, 21 Dunbar Road, Byron, \\ GA 31008
}

Parshall B. Bush

Agricultural Services Laboratory, University of Georgia, 2300 College Station Road, Athens, GA 32602

Additional index words. captan, carbaryl, methyl parathion, packing line, phosmet, propiconazole, Prunus persica

\begin{abstract}
To discern how the packing process influences pesticide residue loads on peach (Prunus persica L. Batsch) fruit; postharvest, post hydrocooled, and post brushed fruit were assessed for levels of several pesticides. The packing house process reduced pesticide residue levels on fresh peaches to levels that were generally below detection limits of our assays in 1998. Carbaryl and captan residues from field packed fruit were $32.2 \times$ and $21.9 \times$, respectively, of that found in the peel of fruit processed in the packing house in 1998 . Carbaryl levels were not reduced by hydrocooling but postharvest brushing reduced pesticide residues up to $94 \%$ in fruit peel. Across processing operations and cultivars assessed in 1999, hydrocooling, hydrocooling plus brushing, and brushing alone removed $37 \%, 62 \%$, and $53 \%$, respectively, of the encapsulated methyl parathion residues from fruit peel. Hydrocooling had the greatest impact on phosmet removal from peel, reducing levels by $\mathbf{7 2 . 5 \%}$. After hydrocooling, phosmet was $5.7 \times$ following brushing in one-half of the subsequent samples. This increase occurred at all three farms, suggesting that periodic cleaning of brushes may be necessary to prevent later contamination of peach peel with pesticides. In the only example in which propiconazole residue remained on peaches at picking, it was removed most effectively $(69 \%)$ by the brushing operation. Nearly $31 \%$ of the propiconazole was removed in the hydrocooler. The packing process before shipment to retail outlets was generally effective in the removal of pesticides that may be present on peel at the time of harvest. Assessment of pesticide residue levels in peach flesh was uniformly below the levels of detection in our assays, suggesting that the classes of pesticide analyzed in peaches were not transepidermal.
\end{abstract}

Knowledge of pesticide residues in our food supply influences decisions made by regulatory agencies to reduce risks to consumers from dietary intake of pesticides. Generally, fruits and vegetables have been assessed for pesticides without consideration of the effects of postharvest handling on the residue load (Erner and Coggins, 1989; Mattern et al., 1990; Metwally et al., 1997; Schattenberg and Hsu, 1992). Additionally, there is increased interest by brokers in field run fruit and by growers in the market for juicing fruit. Therefore, an understanding of the impact of postharvest handling on the reduction of pesticide residues is relevant.

Two aspects of the packing house process, hydrocooling and brushing, are likely to impact peel residue levels of packed peaches (Prunus persica L. Batsch). Hydrocooling serves two roles in the packing process: quick removal of fruit field heat and removal and

Received for publication 20 Mar. 2001. Accepted for publication 5 Sept. 2001. This research was supported by the Georgia Agricultural Commodity Commission for Peach and Georgia Peach Council. ${ }^{1}$ To whom reprint requests should be sent. E-mail address: kctaylor@uga.edu reduction of fruit pathogenic organisms that shorten fruit shelf life (Mitchell, 1989). Brushing is conducted on the packing line to remove trichomes that are unsavory to consumers and to evenly distribute waxes on the fruit surface (Mitchell and Kader, 1989). The impacts of these packing house processes on pesticide residue levels on the peel are important, because portions of the packing house process are circumvented in "tree ripe" programs that often ship somewhat riper field packed fruit over short distances. This study determined the levels of several pesticide residues in the peel of peach fruit, and assessed the value of the washing (hydrocooling) and brushing operations in the packing process vs. no packing house process (field packing).

\section{Materials and Methods}

In these experiments, peach fruit peel was analyzed for several pesticides used as cover sprays during fruit development in the Southeastern U.S. peach industry. Sampling focused on peel rather than whole fruit to capture the majority of pesticide residues without the diluting effect of the peach flesh. The studies, performed on several cultivars of fruit chosen from the early ('Juneprince'), middle ('Harvester'), late ('Flameprince' and 'O'Henry') and very late ('Parade') harvest seasons, fairly represent the full range of pesticide use patterns. Three different grower operations were sampled based on the differences in field operations among those operations (Table 1). Farm A and C sprayed methyl parathion from every row middle at a lower rate than Farm B where methyl parathion was sprayed in alternate row middles. Farm $\mathrm{C}$ was located in an area with slightly different insect and disease pressures, resulting in somewhat reduced application rates and frequencies.

1998 Trial. 'Flameprince' and 'O'Henry' peel samples, taken before and after packing house process, were analyzed for methyl parathion, fenbuconazole, propiconazole, captan and carbaryl. Farm records indicated that the following spray rates were applied by an airblast sprayer at $935 \mathrm{~L} \cdot \mathrm{ha}^{-1}: 1.17 \mathrm{~L} \mathrm{~L} \cdot \mathrm{ha}^{-1}$ methyl parathion (Penncap $\mathrm{M}^{\circledR}$; Elf Atochem, Philadelphia) on 8 Apr. 1998, 15 May 1998, and 4 June 1998; $140 \mathrm{~g} \cdot \mathrm{ha}^{-1}$ fenbuconazole (Indar $^{\circledR} 75 \mathrm{~W}$; Rohm and Haas, Philadelphia) on 15 July 1998; $6.7 \mathrm{~kg} \cdot \mathrm{ha}^{-1}$ (Captan $^{\circledR} 50 \mathrm{~W}$; Micro Flo, Lakeland, Fla.) on 23 June 1998; and $3.3 \mathrm{~kg} \cdot \mathrm{ha}^{-1}$ carbaryl (Sevin ${ }^{\circledR} 80 \mathrm{~S}$; Rhone Poulenc, Research Triangle Park, N.C.) on 19 June 1998. 'Flameprince' were harvested 17 July 1998 and 'O'Henry' on 24 July 1998. Fruit samples were collected prior to hydrocooling (cooling fruit with $\approx 3{ }^{\circ} \mathrm{C}$ recycled water spray) and at the end of the packing line. Fruit collected after the packing process had undergone hydrocooling and brushing. Hydrocooler water contained 25 50 free chlorine $\mathrm{mg} \cdot \mathrm{L}^{-1}$. Fruit were in the hydrocooler for $\approx 40$ min at $\approx 3^{\circ} \mathrm{C}$ and brushed for 25-30 s. Sampled fruit were transported for up to $30 \mathrm{~min}$. in air conditioning and immediately peeled by hand with stainless steel knives in the lab. About $25 \%$ of the peel from each of three fruit was peeled in long strips along the middle portion of the fruit longitudinally from pedicel to pistil scar or tip. The peel was coarsely chopped and $2 \mathrm{~g}$ of the peel composite constituted a single sample. Each cultivar assessed was done so in three replicates for each grower/packer in the study. The isolated peel was placed in a clean glass jar and frozen at $-20{ }^{\circ} \mathrm{C}$ until analysis was performed at the pesticide analysis facility at the Univ. of Georgia Agricultural and Environmental Services Laboratory, Athens, Ga.

1999 Trial. During 1999, more lots were sampled throughout the season and from different farms to reflect changes in field protocols that may influence residue levels. Harvest dates and dates and rates of application in 1999 per farm operation are presented in Table 1. Samples were collected from field bins before and after hydrocooling, and from the packing line after brushing to determine which operation had the greatest influence on reducing pesticide residues. "Brushing only" fruit did not undergo hydrocooling. Farm records indicated different spray rates and protocols for the three operations, but all operations applied pesticides by an airblast sprayer at $\approx 153 \mathrm{~L} \cdot \mathrm{ha}^{-1}$. Relative to 1998 , the detection 
Table 1. Application and sample dates per peach cultivar with pesticide application rates on three farms. All farms applied their pesticides in 100-gal volume per acre.

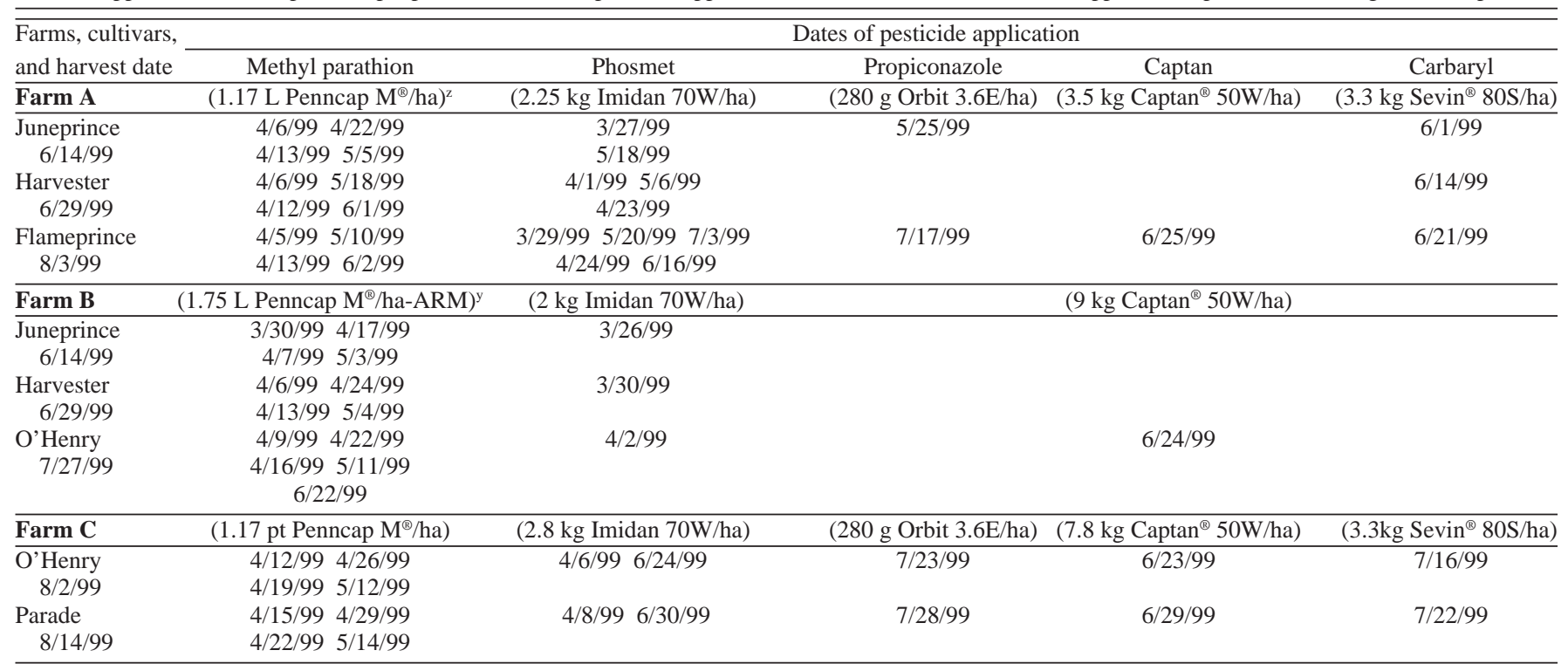

z( ), application rate used by each farm.

yFarm B applied methyl parathion in alternate row middle pattern throughout the season.

limit in 1999 for all pesticide residues was lowered by increasing the sample size 10-fold, without increasing the extraction volume. Five cultivars of peaches with harvest dates that span the season were chosen for the study: 'Juneprince' (14 June 1999); 'Harvester' (29 June 1999); 'O'Henry' (27 July 1999); 'Flameprince' (3 Aug. 1999); and 'Parade' (10 Aug. 1999). Fruit sampled after the hydrocooling step had been hydrocooled for $\approx 42 \mathrm{~min}$ at $\approx 3{ }^{\circ} \mathrm{C}$ in hydrocooler water that contained $25-50$ free chlorine $\mathrm{mg} \cdot \mathrm{L}^{-1}$. Fruit sampled after brushing received $35 \mathrm{~s}$ of brushing at a roller speed of $86 \mathrm{rpm}$ over nylon on polyvinylchloride brushes. Sampled fruit were immediately peeled in the lab as in 1998. Farm $\mathrm{C}$ fruit was shipped to our location by an overnight service and sampled the day of receipt. Peeling strips were pooled from three fruits, coarsely chopped and $20 \mathrm{~g}$ of the peel composite constituted a single sample per handling point and cultivar. The isolated peel from each postharvest handling point were frozen immediately in a glass container and maintained at $20{ }^{\circ} \mathrm{C}$ until analyses were conducted. In addition, fruit flesh samples were taken from the 'Parade' fruit from Farm C in 1999. A 20-g aliquot of the peach flesh homogenate from the same three fruit constituted a sample. Peel from three replicates for each cultivar/harvest date were analyzed for each pesticide listed in Table 1. Flesh from three replicates of 'Parade' fruit were also tested for all applicable pesticides as previously described.

The total peel or flesh composite sample was extracted for residue analysis. Mean peel residue was determined by averaging the residue levels of three replicate samples pooled from three fruit for each cultivar studied at each farm for each field packed or postharvest packing step. Pesticide residues were extracted with ethyl acetate, cleaned by gel permeation chromatography and analyzed using a Trametrics 9001 gas chromatograph (GC) with attached N-P detector (Austin, Texas). Positive pesticide residues were confirmed by GCMass Spectroscopy. The GC columns utilized were a SPB-5 or a SPB-35 megabore capillary column (30 m length). The column oven was temperature programmed with an initial temperature of $135{ }^{\circ} \mathrm{C}$, held for $1 \mathrm{~min}$., followed by a programmed temperature increase of $135^{\circ} \mathrm{C}$ to $275^{\circ} \mathrm{C}$ at $5^{\circ} / \mathrm{min}$. The final $275^{\circ} \mathrm{C}$ temperature was held for $5 \mathrm{~min}$. The complete pesticide analysis included captan, carbaryl, chlorothalonil, chlorpyrifos, dimethoate, fenbuconazole, ethion, phosmet, malathion, parathion, methyl-parathion, and propiconazole. Recovery is reported for the parent compound residues. No attempt was made to determine metabolites or breakdown products such as 1-naphthol from carbaryl.

A fortified sample and reagent blank were included with each set of analyses with GC grade standards for fortification and GC quantification (Accustandard, New Haven, Conn.). Pesticide residues were determined by a general nonionic screening adapted from the Food and Drug Administration Pesticide Analytical Manual optimized for the recovery of methyl parathion, parathion, malathion, and ethion. Other pesticides listed in Table 2 are recovered to varying degrees. The high recovery for captan and dimethoate (not initially targeted compounds) reflect differential GC responses in the peach extract vs. standard in pure solvent. The average residue recoveries, fortification levels, standard deviations of recoveries and number of replicates of recovery assays are given in Table 2 . Reported residue levels were not corrected for percent recovery.

In addition to the peel samples collected in 1999, flesh samples were collected from ' $\mathrm{Pa}$ rade' fruit from Farm C. Fruit were sampled from the field bin before and after hydrocooling, and from the line after brushing. Flesh from the three fruit were combined, and homogenized.
A 20-g aliquot of the ground peach flesh from three fruit constituted a single sample. A mean flesh residue value was obtained by averaging the residue levels of three replicate samples pooled from three fruit for each field packed or postharvest packing step. When appropriate, means were separated by Duncan's multiplerange test (Little and Hills, 1978).

\section{Results and Discussion}

The U.S. Environmental Protection Agency's (USEPA) whole fruit tolerance maximum (USEPA, 1999) for each pesticide tested is listed in Tables 3 and 4. In all cases, the residue levels in peel sampled from field packed fruit were below USEPA tolerance levels established for whole fruit (peel plus flesh). Our study is unique in that the fruit peel (Table 3 and 4) minus the flesh (Table 5) was used in our assays to increase the likelihood of detecting any pesticide residue present on the fruit. Therefore the data in these tests must be viewed with caution. With whole fruit weights ranging from $87-135 \mathrm{~g}$, our 20 -g peel samples from three fruit represent $4.9 \%$ to $7.7 \%$ of the whole fruit mass. Thus, the flesh diluted the residue concentration in whole fruit samples by an average of 12.3-fold (range of dilution = 9 to 13 , data not shown). Avoidance of this $\approx 12$ fold dilution, allowed us to determine residue levels on washed and brushed fruit, within the detection range of our protocols and instrumentation. As an example, had we used whole fruit samples, the methyl parathion level for the 'O'Henry' fruit from Farm B (Table 4) would have been below the detection limit for each stage of the packing line operation tested and would have been just at the detection limit $\left(0.05 \mu \mathrm{g} \cdot \mathrm{g}^{-1}\right)$ in the field packed fruit, and all other methyl parathion tests in 1999 would have been below the detection limit.

Dates of pesticide application and rates of application per farm operation are presented in 
Table 2. Pesticide recovery: percentage of fortified gas chromatograph standards for each pesticide. $^{2}$

\begin{tabular}{lcccc}
\hline \hline Pesticide & $\begin{array}{c}\text { No. } \\
\text { replications }\end{array}$ & $\begin{array}{c}\text { Fortification } \\
\text { level }\left(\mu \mathrm{g}^{-1}\right)\end{array}$ & $\begin{array}{c}\text { Avg recovery } \\
(\%)\end{array}$ & $\begin{array}{c}\text { Recovery } \\
(\mathrm{sD})\end{array}$ \\
\hline Captan & 1 & 0.25 & 134 & --- \\
Carbaryl & 1 & 0.25 & 101 & --- \\
Chlorothalonil & 3 & 0.25 & 87.3 & 17.2 \\
Chlorpyrifos & 1 & 0.25 & 113 & --- \\
Dimethoate & 1 & 0.25 & 128 & --- \\
Ethion & 4 & $0.25 \& 0.48$ & 103 & 13.2 \\
Phosmet & 1 & 0.25 & 97.8 & --- \\
Malathion & 4 & $0.25 \& 0.48$ & 88.8 & 7.44 \\
Parathion & 4 & $0.25 \& 0.48$ & 93.4 & 8.06 \\
Methyl parathion & 4 & $0.25 \& 0.48$ & 96.4 & 3.35 \\
Propiconazole & 4 & 0.25 & 72.4 & 4.48 \\
\hline
\end{tabular}

${ }^{\mathrm{z}} \mathrm{A}$ different fortification sample was run with each set of sample analysis; therefore recoveries are run on different days. Captan, chlorpyrifos, dimethoate, and phosmet are routinely analyzed with quantitative recovery. Only one sample set was fortified with these standards.

Table 1 . When farm by farm comparisons were made by analysis of variance, there was no difference for any pesticide applied with the farm as a main effect. Thus, the rates of application and the use of alternate row middle application at Farm B did not have a statistically significant effect on residue levels.

1998 Trial. The results of the 1998 experiment (Table 3) suggested that significant levels of pesticides were removed by the packing house process. The residue levels of carbaryl and captan were $32.2 \times$ and $21.9 \times$, respectively, higher in the peel from field packed fruit than in the peel from fruit that had been run through the packing house. The overall residue level on house run fruit was negligible or below analytical detection limits. Our data showed that the packing house process reduced methyl parathion, propiconazole, captan and carbaryl residue levels in peel.

1999 Trial. With increased interest in field run fruit and the market for juicing \#2 fruit, it is essential to identify the aspect(s) of the packing process that remove pesticides. Therefore in 1999, residue levels were determined in peels from field run peaches, peels after washing, after washing and brushing and after brushing alone. Hydrocooling and brushing each reduced the residue load to some degree for most pesticides studied (Table 4). Methyl parathion was detected in all samples. Generally, methyl parathion levels were substantially reduced with hydrocooling and brushing operations. Across all cultivars and farms, brushing alone reduced methyl parathion residues by $52.7 \%$, while hydrocooling fruit accounted for a $37 \%$ reduction. The two operations together resulted in a $61.8 \%$ reduction in methyl parathion residue.

Phosmet residue was reduced $72.5 \%$ by hydrocooling but increased $5.7 \times$ by brushing in one-half of the samples after hydrocooling. The largest increase (+940) was over a very small value, $0.005 \mu \mathrm{g} \cdot \mathrm{gm}^{-1}$ in the 'O'Henry' cultivar at Farm C (Table 4), and not above the USEPA tolerance level for phosmet. This increase happened at all three farms, suggesting that periodic cleaning of brushes or other aspects of the line may be necessary to prevent later contamination of peach peel with pesticides, particularly phosmet. Propiconazole was detected only in 'Flameprince' at Farm A. In that case, brushing alone removed $69.3 \%$ of propiconazole residue, but hydrocooling did not reduce residue levels. The operations together reduced propiconazole residue levels by at least $88.3 \%$, well below the tolerance level of $1 \mu \mathrm{g} \cdot \mathrm{gm}^{-1}$ (Table 3 and 4) and even in one case below the level of detection for the analysis $(0.05$ $\left.\mu \mathrm{g} \cdot \mathrm{gm}^{-1}\right)$. Generally, captan was not used by the industry in 1999. Captan was present in only three cultivars: 'Flameprince' (Farm A), 'O'Henry (Farm B)', and 'Parade' (Farm C). The averages of the means for captan residues on the captan-treated fruit from all three farms were examined and brushing was very important for residue removal, overall removing at least $78.7 \%$ of the captan residue from the fruit processed. Hydrocooling reduced captan levels in 'O'Henry' (72.5\%) and 'Parade' (39.5\%) from Farms B and C, respectively, while brushing reduced residue levels in all three facilities $(88.3 \%, 79.2 \%$, and $68.5 \%$, respectively). Although substan- tial levels of captan were found in peel samples, they were all below the whole fruit maximum tolerance of $50 \mu \mathrm{g} \cdot \mathrm{gm}^{-1}$. Carbaryl (Sevin ${ }^{\circledR} 80 \mathrm{~S}$ ) was generally used as a nearharvest insecticide to avoid the long postharvest intervals of Penncap $\mathrm{M}^{\circledR}$, Guthion and Imidan. Carbaryl was detected in all of the cultivars tested at Farm A. The 'Harvesters' and the 'Flameprince' had residue reductions with postharvest handling. These values were most reduced in the brushing operation. Carbaryl levels were not reduced by hydrocooling, while brushing reduced the levels by as much as $94 \%$.

These results indicate that the brushes or possibly rollers on the packing line should be cleaned periodically to remove pesticide residues that can accumulate and contaminate clean fruit. The necessity for such cleaning may be particularly true in the case of phosmet, that was applied as a wettable powder, and so may be more likely to accumulate on brushes or other portions of the packing line than do other formulations. Likewise, carbaryl appeared to accumulate in hydrocooler waters and recontaminate fruit, building to levels somewhat higher than that present on fruit prior to hydrocooling as with 'Juneprince' at Farm A. The carbaryl formulation was a wettable powder that could easily be redeposited on fruit if it accumulated in the cold hydrocooler waters.

Except for methyl parathion, residue levels in peach flesh (Table 5) were below analytical detection limits, and this value was barely detectable in hydrocooled fruit. This finding suggests that these pesticides are poorly transported across the peel into the flesh. Other studies report that residue levels in whole fruit can be diminished by the water in the flesh or pulp of the commodity (Hsu et al., 1991; Liu et al., 1991; Mattern et al., 1990; Metwally et al., 1997; Schattenberg et al., 1996). We purposely focused on the peel for the purpose of observing very high pesticide levels and in one case separated the flesh to demonstrate the low level of contaminant that makes its way into the flesh. As an example, the methyl parathion level for the 'O'Henry' fruit from Farm B would have been below the detection limit for each stage of the packing line operation tested and would have been just at the limit of detection $\left(0.05 \mu \mathrm{g} \cdot \mathrm{gm}^{-1}\right)$ in the field packed fruit.

Despite the use of peel tissue samples (minus flesh tissue) in our tests, samples from all peach varieties and farms were below the USEPA tolerance levels. Given the potential

Table 3. Peel residues of four pesticides on field and packing house packed peaches (1998 study), and maximum tolerance values [U.S. Environmental Protection Agency (USEPA)].

\begin{tabular}{|c|c|c|c|c|}
\hline Tolerance ${ }^{y}$ & $\begin{array}{c}\text { Methyl parathion } \\
\left(1.17 \text { pt Penncap } \mathrm{M}^{\circledast} / \mathrm{ha}\right)^{\mathrm{z}} \\
1 \mu \mathrm{g} \cdot \mathrm{g}^{-1}\end{array}$ & $\begin{array}{c}\text { Fenbuconazole } \\
\left(140 \mathrm{~g} \mathrm{Indar}^{\circledast} 75 \mathrm{~W} / \mathrm{ha}\right) \\
2 \mu \mathrm{g} \cdot \mathrm{g}^{-1}\end{array}$ & $\begin{array}{c}\text { Captan } \\
\left(6.7 \mathrm{~kg} \mathrm{Captan}{ }^{\circledast} 50 \mathrm{~W} / \mathrm{ha}\right) \\
50 \mu \mathrm{g}^{-1}\end{array}$ & $\begin{array}{c}\text { Carbaryl } \\
\left(3.3 \mathrm{~kg} \mathrm{Sevin}{ }^{\circledast} 80 \mathrm{~S} / \mathrm{ha}\right) \\
10 \mu \mathrm{g}^{-1}\end{array}$ \\
\hline Field packed & $0.25^{\mathrm{x}}$ & 0.12 & 13.33 & 1.61 \\
\hline House packed & $<0.10$ & $<0.050$ & 0.61 & 0.05 \\
\hline Detection limits & 0.10 & 0.050 & 0.20 & 0.05 \\
\hline Significance level & * & NS & ** & $* *$ \\
\hline
\end{tabular}

${ }^{z}()=$ application rate used

'Tolerance $=$ USEPA maximum tolerance value (USEPA, 1999).

${ }^{x}$ All results are reported for peel tissue only, which constituted $0.5 \%$ to $0.7 \%$ of the total fruit mass in the 1998 test.

ss, *** Nonsignificant or significant at $P<0.05$ or 0.01 , respectively, by analysis of variance. 
Table 4. Peel residues of five pesticides from three farms and four cultivars in 1999, and maximum tolerance values (U.S. Environmental Protection Agency).

\begin{tabular}{|c|c|c|c|c|c|}
\hline Tolerance $^{\mathrm{z}}$ & $1 \mu \mathrm{g} \cdot \mathrm{g}^{-1}$ & $10 \mu \mathrm{g} \cdot \mathrm{g}^{-1}$ & $1 \mu \mathrm{g} \cdot \mathrm{g}^{-1}$ & $50 \mu \mathrm{g} \cdot \mathrm{g}^{-1}$ & $10 \mu \mathrm{g} \cdot \mathrm{g}^{-1}$ \\
\hline Farm A & Methyl parathion & Phosmet & Propiconazole & Captan & Carbaryl \\
\hline \multicolumn{6}{|l|}{ Juneprince } \\
\hline Field & $0.123 \mathrm{a}$ & $<0.005$ & $<0.050$ & $<0.200$ & $0.087 \mathrm{~b}$ \\
\hline Post-cooler & $0.107 \mathrm{ab}$ & $<0.005$ & $<0.050$ & $<0.200$ & $1.017 \mathrm{a}$ \\
\hline Post-brushes & $0.079 \mathrm{~b}(-35.8)$ & $<0.005$ & $<0.050$ & $<0.200$ & $0.023 \mathrm{~b}$ \\
\hline Brushing alone & $0.086 \mathrm{~b}(-30.1)$ & $<0.005$ & $<0.050$ & $<0.200$ & $0.053 \mathrm{~b}$ \\
\hline \multicolumn{6}{|l|}{ Harvester } \\
\hline Field & $0.563 \mathrm{a}$ & $0.283 \mathrm{a}$ & $<0.050$ & $<0.200$ & $0.673 \mathrm{a}$ \\
\hline Post-cooler & $0.236 \mathrm{~b}(-58.1)$ & $0.008 b(-97.2)$ & $<0.050$ & $<0.200$ & $0.773 \mathrm{a}$ \\
\hline Post-brushes & $0.171 \mathrm{~b}(-69.6)$ & $0.104 \mathrm{a}$ & $<0.050$ & $<0.200$ & $0.353 \mathrm{~b}(-47.5)$ \\
\hline Brushing alone & $0.195 \mathrm{~b}(-65.4)$ & $0.132 \mathrm{a}$ & $<0.050$ & $<0.200$ & $0.437 \mathrm{~b}(-35.1)$ \\
\hline \multicolumn{6}{|l|}{ Flameprince } \\
\hline Field & $0.332 \mathrm{a}$ & $<0.005$ & $0.427 \mathrm{a}$ & $1.697 \mathrm{a}$ & $0.35 \mathrm{a}$ \\
\hline Post-cooler & $0.216 \mathrm{a}$ & $<0.005$ & $0.295 \mathrm{a}$ & $1.589 \mathrm{a}$ & $0.26 \mathrm{a}$ \\
\hline Post-brushes & 0.008 b (-97.6) & $<0.005$ & $<0.050 \mathrm{~b}(-\geq 88.3)$ & $<0.200 \mathrm{~b}(-\geq 88.3)$ & $<0.05$ b $(-\geq 94.3)$ \\
\hline Brushing alone & $0.047 \mathrm{~b}(-85.8)$ & $<0.005$ & $0.131 \mathrm{~b}(-69.3)$ & $<0.200 \mathrm{~b}(-\geq 88.3)$ & $<0.05$ b $(-\geq 94.3)$ \\
\hline Farm B & Methyl parathion & Phosmet & Propiconazole & Captan & Carbaryl \\
\hline \multicolumn{6}{|l|}{ Juneprince } \\
\hline Field & $0.478 \mathrm{a}$ & $0.862 \mathrm{a}$ & $<0.050$ & $<0.200$ & $<0.05$ \\
\hline Post-cooler & $0.372 b(-22.2)$ & $0.239 \mathrm{c}(-72.3)$ & $<0.050$ & $<0.200$ & $<0.05$ \\
\hline Post-brushes & 0.091 c $(-81.0)$ & $0.549 \mathrm{~b}(-63.7)$ & $<0.050$ & $<0.200$ & $<0.05$ \\
\hline Brushing alone & $0.143 \mathrm{c}(-70.1)$ & $0.390 \mathrm{c}(-54.8)$ & $<0.050$ & $<0.200$ & $<0.05$ \\
\hline \multicolumn{6}{|l|}{ Harvester } \\
\hline Field & $0.119 \mathrm{a}$ & $1.00 \mathrm{a}$ & $<0.050$ & $<0.200$ & $<0.05$ \\
\hline Post-cooler & $0.120 \mathrm{a}$ & $0.519 b(-48.1)$ & $<0.050$ & $<0.200$ & $<0.05$ \\
\hline Post-brushes & $0.114 \mathrm{a}$ & 0.333 c $(-66.7)$ & $<0.050$ & $<0.200$ & $<0.05$ \\
\hline Brushing alone & $0.116 \mathrm{a}$ & $0.387 \mathrm{c}(-61.3)$ & $<0.050$ & $<0.200$ & $<0.05$ \\
\hline \multicolumn{6}{|l|}{ O'Henry } \\
\hline Field & $0.842 \mathrm{a}$ & $<0.005$ & $<0.050$ & $10.573 \mathrm{a}$ & $<0.05$ \\
\hline Post-cooler & $0.408 \mathrm{~b}(-51.5)$ & $<0.005$ & $<0.050$ & $2.903 \mathrm{~b}(-72.5)$ & $<0.05$ \\
\hline Post-brushes & 0.199 c $(-76.4)$ & $<0.005$ & $<0.050$ & $2.183 \mathrm{~b}(-79.4)$ & $<0.05$ \\
\hline Brushing alone & $0.291 \mathrm{c}(-65.4)$ & $<0.005$ & $<0.050$ & $2.198 \mathrm{~b}(-79.2)$ & $<0.05$ \\
\hline Farm C & Methyl parathion & Phosmet & Propiconazole & Captan & Carbaryl \\
\hline \multicolumn{6}{|l|}{ Juneprince } \\
\hline \multicolumn{6}{|l|}{ O'Henry } \\
\hline Field & $0.369 \mathrm{a}^{\mathrm{y}}$ & $<0.005 \mathrm{~b}$ & $<0.050$ & $<0.200$ & $<0.05 \mathrm{a}$ \\
\hline Post-cooler & $0.081 \mathrm{~b}(-78.0)$ & $0.021 \mathrm{a}(+421)$ & $<0.050$ & $<0.200$ & $<0.05 \mathrm{a}$ \\
\hline Post-brushes & $0.131 \mathrm{~b}(-64.5)$ & $0.082 \mathrm{a}(+164)$ & $<0.050$ & $<0.200$ & $0.063 \mathrm{a}$ \\
\hline Brushing alone & $0.187 \mathrm{~b}(-49.3)$ & $0.047 \mathrm{a}(+940)$ & $<0.050$ & $<0.200$ & $0.056 \mathrm{a}$ \\
\hline Field & $0.207 \mathrm{a}$ & $<0.005 \mathrm{~b}$ & $<0.050$ & $5.917 \mathrm{a}$ & $<0.05$ \\
\hline Post-cooler & $0.127 \mathrm{~b}(-38.6)$ & $<0.005 \mathrm{~b}$ & $<0.050$ & $3.577 \mathrm{~b}(-39.5)$ & $<0.05$ \\
\hline Post-brushes & $0.072 \mathrm{c}(-65.2)$ & $0.018 \mathrm{a}(+360)$ & $<0.050$ & $1.380 \mathrm{c}(-76.7)$ & $<0.05$ \\
\hline Brushing alone & $0.098 \mathrm{c}(-52.7)$ & $0.012 \mathrm{a}(+240)$ & $<0.050$ & $1.865 \mathrm{c}(-68.5)$ & $<0.05$ \\
\hline Detection Limits & 0.050 & 0.005 & 0.050 & 0.200 & 0.05 \\
\hline
\end{tabular}

${ }^{2}$ Tolerance $=$ USEPA maximum tolerance value (USEPA, 1999).

${ }^{y}$ All results are reported for peel tissue only, which constituted 5\% to 7\% of the total fruit mass in the 1999 test. Means of three composite samples followed by different letters in the same column for the same cultivar and farm were different at $P \leq 0.05$ by Duncan's multiple-range test. Parenthetical values are percent increases or decreases in residue levels relative to field packed fruit when differences were significant at $P \leq 0.05 \%$.

Table 5. Pesticide residues in flesh of peeled peach fruit. Farm C only.

\begin{tabular}{lccccc}
\hline Farm C & Methyl parathion & Phosmet & Propiconazole & Captan & Carbaryl \\
\hline Parade & ----------- & $\mu \mathrm{g} \cdot \mathrm{g}^{-1}$ & ------------- \\
Field & $<0.005^{z, y}$ & $<0.005$ & $<0.050$ & $<0.200$ & $<0.05$ \\
Post-cooler & 0.006 & $<0.005$ & $<0.050$ & $<0.200$ & $<0.05$ \\
Post-brushes & $<0.005$ & $<0.050$ & $<0.050$ & $<0.200$ & $<0.05$ \\
Brushing alone & $<0.005$ & $<0.005$ & $<0.050$ & $<0.200$ & $<0.05$ \\
\hline
\end{tabular}

${ }^{\mathrm{z}}$ Means presented are of three composite samples.

${ }^{y}$ All results are reported for mesocarp or flesh tissue only, which constituted $78 \%$ to $81 \%$ of the total fruit mass in the 1999 test.

for further reduction of values if whole fruit had been analyzed, postharvest values should be substantially lower than USEPA tolerance levels for whole fruit. The values found in field packed fruit were reduced even more through washing and brushing operations in the packing process. Clearly, the packing process before shipment to retail outlets is extremely effective in removing the pesticide load that may be present at the time of harvest. The washing and brushing operations each contributed to the removal of the pesticides with brushing having the greatest impact on residue reduction. It is evident, however, that care should be taken periodically to clean the brushes or possibly rollers on the packing line and to replace hydrocooler water more often to remove pesticide residues that can accumulate and contami- nate clean fruit. Continued research will assess the cleanup of packing lines and appropriate turnover of hydrocooler waters to avoid pesticide reloading on peel surfaces.

\section{Literature Cited}

Erner, Y. and C.W.Coggins, Jr. 1989. Free and bound residues of 2,4-D in 'Marsh' grapefruit and 'Washington' navel orange fruit. J. Amer. Soc. Hort. Sci. 114:846-850.

Food and Drug Administration. 1994. Pesticide analytical manual. Volume I: Multiresidue methods.

Hsu, J.P., H.J. Schattenberg III, and M.M Garza. 1991. Fast turnaround multiresidue screen for pesticides in produce. J. AOAC International. 74:886-892.

Little, T.M. and F.J. Hills. 1978. Agricultural experimentation, design and analysis: Mean separation. Wiley, New York. p. 61-65.

Liu, C.H., G.C. Mattern, X, Yu, and R.T. Rosen. 1991. Multi-residue determination of non-vola- 
tile and thermally labile pesticides in fruits and vegetables by thermospray liquid chromatography-mass spectrometry. J. Agr. Food Chem. 39:718-723.

Mattern, G.C., G.M. Singer, J. Louis, M. Robson, and J.D. Rosen. 1990. Determination of several pesticides with a chemical ionization ion trap detector. J. Agr. Food. Chem. 38:402-407.

Metwally, M.E.-S., M.S. Osman, and R. Al-Rushaid. 1997. A high performance liquid chromatographic method for the determination of cypermethrin in vegetables and its application to kinetic studies after greenhouse treatment. Food Chem. 59:283290.

Mitchell, F.G. 1989. Cooling, p. 211-214. In: J.H. LaRue and R.S. Johnson (eds.). Peaches plums and nectarines: Growing and handling for fresh marketing. Publication 3331. Univ. of California Regents. Oakland, Calif.

Mitchell, F.G. and A.A. Kader. 1989. Factors affecting deterioration rate, p. 170. In: J.H. LaRue and R.S. Johnson (eds.). Peaches plums and nectarines: Growing and handling for fresh marketing. Publication 3331. Univ. of California Regents.
Oakland, Calif.

Schattenberg, H.J. and J.P. Hsu. 1992. Pesticide residue survey of produce from 1989 to 1991. J. AOAC Intl. 75:925-933.

Schattenberg, H.J. III., P.W. Geno, J.P. Hsu, W.G. Fry, and R.P. Parker. 1996. Effect of household preparation on levels of pesticide residues in produce. J. AOAC Intl. 79:768-774.

United States Environmental Protection Agency. 1999. Code of Federal Regulations. Title 40. Part 180. Tolerances and exemptions from tolerances for pesticides. Chemicals in food. 